\title{
A CLINICAL STUDY OF PSORIASIS AND ITS ASSOCIATION WITH SERUM LIPID PROFILE
}

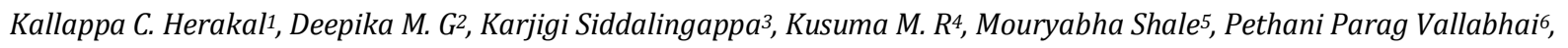
Asmitha Kumari7, Harshavardhan Gowda ${ }^{8}$

1 Professor and HOD, Department of Dermatology, Navodaya Medical College, Hospital and Research Centre, Raichur. 2Junior Resident, Department of Dermatology, Navodaya Medical College, Hospital and Research Centre, Raichur. 3 Professor, Department of Dermatology, Navodaya Medical College, Hospital and Research Centre, Raichur.

${ }^{4}$ Senior Resident, Department of Dermatology, Navodaya Medical College, Hospital and Research Centre, Raichur. 5 Junior Resident, Department of Dermatology, Navodaya Medical College, Hospital and Research Centre, Raichur. 6Junior Resident, Department of Dermatology, Navodaya Medical College, Hospital and Research Centre, Raichur. 7Junior Resident, Department of Dermatology, Navodaya Medical College, Hospital and Research Centre, Raichur. 8Junior Resident, Department of Dermatology, Navodaya Medical College, Hospital and Research Centre, Raichur.

\section{ABSTRACT}

\section{BACKGROUND}

Psoriasis is one of the most common dermatological conditions seen in the daily practice. Psoriasis is known to be associated with lipid profile abnormality, increased fasting blood glucose levels, increased waist circumference and increase in blood pressures which collectively constitute the so called metabolic syndrome.

The objectives of this study- 1 . To study the serum lipid profile among psoriasis patients attending our hospital. 2 . To study serum lipids in relation to the severity of psoriasis among these patients.

\section{MATERIALS AND METHODS}

The study was conducted at Navodaya Medical College Hospital and Research Centre, Raichur. 50 patients of newly diagnosed psoriasis who had not received any prior topical or systemic treatment were randomly selected for the study and matched with 50 age and sex matched controls. A complete lipid profile was estimated with measurement of blood pressure.

Collection of Data- Blood samples were collected after obtaining proper consent from all cases and controls. Serum lipids were measured by enzymatic method.

\section{RESULTS}

A total of 50 consecutive cases of psoriasis were screened, examined and recruited. A detailed history was taken and thorough examination was carried out. 50 age and sex matched controls were also recruited. Blood tests were then carried out to assess levels of total cholesterol, LDL, VLDL and HDL. Majority (26\%) of the patients belonged to 31 - 40 years' age group. Male: female ratio was 3.2: $1.2(4 \%)$, patients had mild psoriasis (PASI < 3), $30(60 \%)$ patients had psoriasis of moderate severity (PASI $3-10)$, whereas $18(36 \%)$ patients had severe type (PASI > 10). Psoriatic arthritis was noted in $12 \%$ ( 6 patients) of the cases. $22 \%$ of the patients had concomitant diabetes, while $16 \%$ of the patients had coexistent hypertension. Amongst the various lipid parameters, slight elevation was found only in triglyceride values, while other parameters like HDL, VLDL, LDL and Total Cholesterol did not show any significant association. Further there was no correlation of abnormality in lipid parameters with the severity of disease.

\section{CONCLUSION}

Our study did not show any association of psoriasis with abnormality in the lipid profile. The plenty of reports from West approving such an association can be explained on the basis of increased prevalence of obesity, abnormal BMI and hypertension as compared to Indian patients.

\section{KEYWORDS}

Psoriasis, Metabolic Syndrome, Psoriasis, Lipid Profile.

HOW TO CITE THIS ARTICLE: Herakal KC, Deepika MG, Siddalingappa K, et al. A clinical study of psoriasis and its association with serum lipid profile. J. Evolution Med. Dent. Sci. 2017;6(23):1898-1904, DOI: 10.14260/Jemds/2017/417

\section{BACKGROUND}

Psoriasis is a common, chronic, disfiguring, inflammatory and proliferative condition of the skin, in which both genetic and environmental influences have a critical role. ${ }^{1}$

Financial or Other, Competing Interest: None.

Submission 23-01-2017, Peer Review 04-03-2017,

Acceptance 11-03-2017, Published 20-03-2017.

Corresponding Author:

Dr. Kallappa C. Herakal,

Professor and HOD,

Department of Dermatology,

Navodaya Medical College, Hospital and

Research Centre, Mantralaya Road, Raichur.

E-mail: deepikamgowda69@gmail.com

DOI: $10.14260 /$ jemds $/ 2017 / 417$

\section{(c) $($ ) $९$} countries. $^{2}$ It is important to recognise that psoriasis is a term that embraces a spectrum of diseases ranging from localised plaques to more severe generalised involvement with or without psoriatic arthritis and associated manifestations of other autoimmune diseases. The prevalence of psoriasis varies from 0.1 to $3 \%^{3}$ and is the greatest in northern colder climates. ${ }^{4}$

Genetic factors play a critical role in the pathogenesis of psoriasis. ${ }^{1}$ Psoriasis tends to worsen during periods of stress, cold weather and low humidity with the administration of certain drugs and during course of certain infections. ${ }^{5}$ Ethnic factors also play an important role. ${ }^{6}$ 
The lesions of psoriasis consist of red, scaly, sharply demarcated, indurated plaques present particularly over extensor surfaces and scalp. The disease is enormously variable in duration, periodicity of flares and extent. ${ }^{1}$

The aetiology of psoriasis is unknown but genetic, metabolic and immunologic mechanisms have been proposed. The loss of scale observed from the surface from the lesions in the course of the disease may be related to lipid disorders in epidermis and in the serum. ${ }^{7}$

Psoriasis is a complex systemic inflammatory dermatological disease that effects an estimated $2-3 \%$ of total population worldwide. 8 Almost half a century ago Lea, Cornish and Block reported increased serum lipid concentrations in patients. Changes in the plasma lipid composition may be the reason for increased risk of atherosclerosis in psoriasis. ${ }^{9}$ Alterations in plasma lipid and lipoprotein composition including a tendency toward an increase in Total Cholesterol (TC), Triglyceride (TG), Low Density Lipoprotein Cholesterol (LDL- C) and decrease in High-Density Lipoprotein Cholesterol (HDL- C) levels suggest that psoriasis may be associated with the disorders of lipid metabolism. ${ }^{10,11}$

It has been suggested that psoriasis is associated with metabolic syndrome. Dermatologists taking care of patients with psoriasis should be aware of this association and advice the patients to reduce additional risk factors such as smoking. ${ }^{12}$ Further the development of certain side effects following systemic therapy are much more common in diabetics as compared to general population, so caution must be exercised in such subjects. 13

The present study was undertaken to know more about the epidemiological and clinical profile of the disease and to assess its association with deranged lipid profile which act as risk factors for cardiovascular disease in these patients.

\section{MATERIALS AND METHODS \\ Source of Data}

The study comprised of 50 consecutive cases of psoriasis visiting the inpatient and outpatient Department of Dermatology of Navodaya Medical College Hospital and Research Centre, Raichur.

\section{Methodology and Type of Data Collected}

After obtaining clearance and approval from the Institutional Ethical Committee, 50 consecutive cases were included in the study. After obtaining informed consent a detailed history including demographic data, drug history, personal history, family history, present and past medical history, emotional stress and exposure to sexually transmitted diseases were taken. The data was collected in proforma and 50 age and sex matched controls were also recruited. Relevant laboratory investigations were done to diagnose any underlying disease states and other organ/system involvement. Biopsy was done in doubtful cases after obtaining a written consent from the patient.

\section{Inclusion Criteria}

All clinically diagnosed new cases of psoriasis $>18$ years of age.

\section{Exclusion Criteria}

Patients not willing to take part in the study or unwilling to give their written consent for the study.
Pregnant patients and patients with liver disease, renal disorder and HIV.

Patients treated earlier or on treatment.

\section{Sample Size}

A total of 100 cases were investigated (50 cases and 50 control).

\section{Study Duration}

January 2014 to July 2015 (18 months).

\section{Study Design}

Descriptive Study.

\section{Sample Design}

Purposive Sampling.

\section{History and Examination}

A detailed history was taken pertaining to the duration of psoriasis, treatment taken for psoriasis, family history of psoriasis, occupation, drug intake other than for psoriasis, personal history of diabetes, hypertension, cardiac events, smoking and alcohol intake.

All the patients were subjected to general physical examination and cutaneous examinations. Height and weight of all patients were recorded. All the patients were graded according to Psoriasis Area Severity Index (PASI) and Body Surface Area (BSA) into 3 categories- Mild, Moderate and Severe. All the changes involving nails, scalp and genitalia were documented as per the proforma.

\section{Scores}

The patients were classified based on Psoriasis Area Severity Index (PASI) and Body Surface Area (BSA).

\section{PASI}

Is a useful tool in monitoring the response of psoriasis to any therapeutic regimen. Four sites of affection- head (h), upper limbs (u), trunk (t) and lower limbs (l) are separately scored. Morphologic scoring of psoriasis plaques is done by evaluation of three parameters- erythema, induration and desquamation, each of which is graded on a severity scale of 0 to 4 where $0=$ nil, $1=$ mild, $2=$ moderate, $3=$ severe and 4 $=$ very severe. The addition of these scores for each site is multiplied by the grading for area wise percentage involvement of that particular site in the following manner: $1=$ less than $10 \%$ area, $2=10-29 \%, 3=30-49 \%, 4=50 \%$ $69 \%, 5=70 \%-89 \%, 6=>90 \%$. Since the four body region (Head, upper limbs, trunk and lower limbs) represent about $10 \%, 20 \%, 30 \%$ and $40 \%$ of body surface area respectively, they are given corresponding weightage in scoring by multiplying their scores by $0.1,0.2,0.3$ and 0.4 respectively. Hence, the final formula for calculating PASI score is as follows-

PASI $=0.1(E b+I h+D h) A+0.2(E u+I u+D u) A+0.3(E t$ $+\mathrm{It}+\mathrm{Dt}) \mathrm{A}+0.4(\mathrm{El}+\mathrm{Il}+\mathrm{Dl}) \mathrm{A}$

The score can vary between 0 and 72 in steps of 0.1 -

One limitation of the PASI score lies in its interobserver variation, which makes evaluation by the same evaluates necessary and the consensuses are arrived after 2 clinician's observations. 
In our Study-

Psoriasis Area Severity Index (PASI)

Graded as,

Mild (PASI < 3),

Moderate (PASI $>3$ - 10),

Severe (PASI $>10$ ).

\section{Body Surface Area (BSA)}

BSA was calculated using rule of nine and was graded as-

Mild (BSA < 10),

Moderate (BSA 10 - 20),

Severe $(B S A>20)$.

\section{Method of Collection of Data \\ Specimen Collection \\ Blood}

$5 \mathrm{~mL}$ plain venous blood after overnight fasting was obtained by vene puncture. This was followed by centrifugation and then sample was processed immediately after collection.

\section{Statistical Analysis}

Case control statistical analysis was carried out in the present study. Results on continuous measurements are presented on mean \pm SD (Min - Max) and results on categorical measurements are presented in Number (\%). Significance is assessed at $5 \%$ level of significance.

\section{RESULTS}

A total of 50 cases of psoriasis were screened, examined and recruited. A history was taken and thorough examination was carried out. 50 age and sex matched controls were also recruited.

\section{Age and Sex}

Mean age of cases was 37.26 years, while mean age of the controls was 40.2 years. Majority (26\%) belonged to the age group of 31 - 40 years and there were less patients in the 11 20 years' and 61 - 80 years' age group with prevalence being $12 \%$ and $4 \%$ respectively. The age distribution of the cases and controls is presented in Table 1 and projected graphically in Graph 1. There were 38 males and 12 females. The ratio of male-to-female ratio was $3.2: 1$. The ratio in controls was 2.5:1. Results are displayed in Table 2 and projected graphically in Graph 2.

\section{Severity of Psoriasis}

The severity of psoriasis was graded according to the PASI score. According to PASI, 2 (4\%) patients had mild psoriasis (PASI < 3), $30(60 \%)$ patients had psoriasis of moderate severity (PASI 3 - 10), whereas 18 (36\%) patients had severe type (PASI > 10). Results are displayed in Table 3 and Graph 3.

\section{Prevalence of Diabetes}

$22 \%$ of the cases had diabetes, while only $16 \%$ of the controls had diabetes. There was no significant association ( $\mathrm{p}$ value: 0.941). Results are displayed in Table 5 and Graph 5.

\section{Prevalence of Hypertension}

$16 \%$ of the cases had hypertension, while only $8 \%$ of the controls were hypertensives (Table 6, Graph 6). There was not a significant association ( $\mathrm{p}$ value: 0.841 ).
No association was noted between the prevalence of hypertension and abnormalities in lipid parameters.

\section{Lipid Profile}

$96 \%$ of the cases of psoriasis had serum cholesterol values within the normal range as compared to $98 \%$ of controls. Thus, no significant difference in cholesterol values was seen in cases and controls ( $p$ value 0.0001 ). The results have been demonstrated in Table 7 and 8 and depicted graphically in Graph 7. The mean value of serum cholesterol in cases was $198.46 \mathrm{mg} / \mathrm{dL}$, which was comparable to the mean value in controls $197.74 \mathrm{mg} / \mathrm{dL}$ ( $\mathrm{p}$ value 0.891 ). The results have been depicted in Table 7 and 8 and displayed in Graph 7.

$88 \%$ of the cases had serum triglycerides within the normal range as compared to $90 \%$ of the controls. Thus, no significant difference in serum triglyceride values was seen in cases and controls ( $p$ value 0.0001 ). However, the mean value in cases was 148.16, which was significantly lower than the mean value in controls which was 163.46. ( $P$ value 0.096). The results have been depicted in Table 7 and 8 and displayed in Graph 8.

$96 \%$ of the cases had serum HDL within the normal range as compared to $98 \%$ of the controls. Thus, no significant difference in HDL values was seen in cases and controls ( $\mathrm{p}$ value 0.0001 ). The mean value of serum HDL in cases was $42.32 \mathrm{mg} / \mathrm{dL}$, which was comparable to the mean value in controls $40.04 \mathrm{mg} / \mathrm{dL}$ ( $\mathrm{p}$ value 0.227 ). The results have been depicted in Table 7 and 8 and displayed in Graph 9.

$86 \%$ of the cases had serum VLDL within the normal range as compared to $90 \%$ of the controls. Thus, no significant difference in VLDL values was seen in cases and controls. The mean values of VLDL in cases and controls were 28.82 and 26.90 respectively ( $p$ value 0.0001 ). No significant association was seen in VLDL values between cases and controls ( $p$ value 0.377 ). The results have been depicted in Table 7 and 8 and displayed in Graph 10.

$94 \%$ of the cases had serum LDL within the normal range as compared to $98 \%$ of the controls. Thus, no significant difference in LDL values was seen in cases and controls ( $p$ value 0.0001). Mean LDL values in cases was 153.1, while mean value in controls was 143.30. The association was not found to be significant ( $\mathrm{p}$ value 0.031 ). The results have been depicted in Table 7 and 8 and displayed in Graph 11.

\begin{tabular}{|c|c|c|c|c|}
\hline $\begin{array}{c}\text { Age in } \\
\text { Years }\end{array}$ & \multicolumn{2}{|c|}{ Cases } & \multicolumn{2}{c|}{ Control } \\
\hline & No. & $\%$ & No. & $\%$ \\
\hline $11-20$ & 06 & 12.0 & 04 & 8.0 \\
\hline $21-30$ & 12 & 24.0 & 14 & 24.0 \\
\hline $31-40$ & 13 & 26.0 & 14 & 24.0 \\
\hline $41-50$ & 07 & 14.0 & 09 & 18.0 \\
\hline $51-60$ & 10 & 20.0 & 11 & 22.0 \\
\hline$>60$ & 02 & 4.0 & 02 & 4.0 \\
\hline Total & $\mathbf{5 0}$ & $\mathbf{1 0 0 . 0}$ & $\mathbf{5 0}$ & $\mathbf{1 0 0 . 0}$ \\
\hline $\begin{array}{c}\text { Mean } \\
+/-S D\end{array}$ & 37.26 & & 40.20 & \\
\hline \multicolumn{2}{|c|}{ Table 1. Age Wise Distribution of Cases and Control } \\
\hline
\end{tabular}




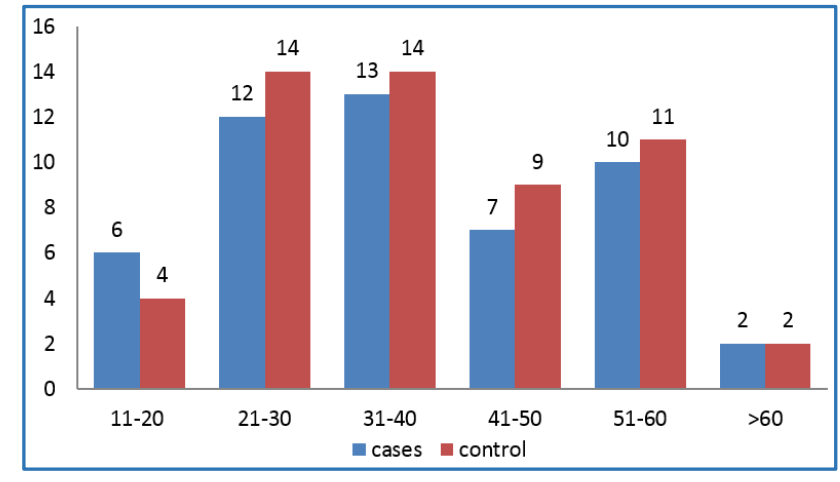

Graph 1. Age Wise Distribution of Cases and Control

\begin{tabular}{|c|c|c|c|c|}
\hline \multirow{2}{*}{ Gender } & \multicolumn{2}{|c|}{ Cases } & \multicolumn{2}{c|}{ Control } \\
\cline { 2 - 5 } & No & $\mathbf{\%}$ & No & \% \\
\hline Male & 38 & 76.0 & 36 & 72.0 \\
\hline Female & 12 & 24.0 & 14 & 28.0 \\
\hline Total & $\mathbf{5 0}$ & $\mathbf{1 0 0 . 0}$ & $\mathbf{5 0}$ & $\mathbf{1 0 0 . 0}$ \\
\hline Table 2. Gender Distribution of Cases and Controls \\
\hline
\end{tabular}

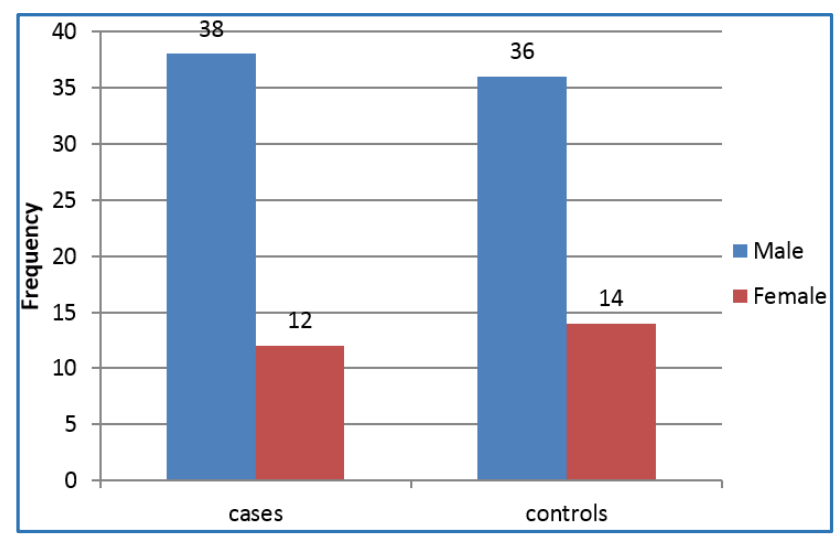

Graph 2. Gender Distribution of Cases and Controls

\begin{tabular}{|c|c|c|}
\hline PASI & Number of Cases & \% \\
\hline Mild & 02 & 4.0 \\
\hline Moderate & 30 & 60.0 \\
\hline Severe & 18 & 36.0 \\
\hline Total & $\mathbf{5 0}$ & $\mathbf{1 0 0 . 0}$ \\
\hline \multicolumn{2}{|c|}{ Table 3. Distribution of Cases according } \\
to Psoriasis Area Severity Index \\
\hline
\end{tabular}

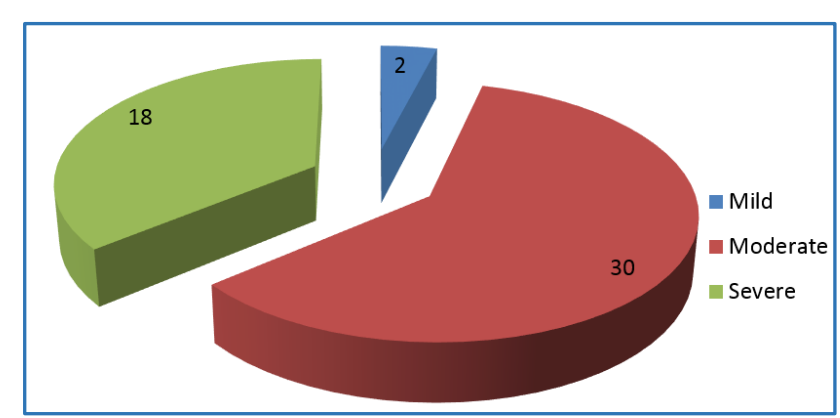

Graph 3. Distribution of Cases according to Psoriasis Area Severity Index

\begin{tabular}{|c|c|c|}
\hline Psoriatic Arthritis & No. of Patients & $\mathbf{\%}$ \\
\hline Yes & 06 & 12.0 \\
\hline No & 44 & 88.0 \\
\hline Total & $\mathbf{5 0}$ & $\mathbf{1 0 0 . 0}$ \\
\hline \multicolumn{2}{|c|}{ Table 4. Distribution of Psoriatic Arthritis in Patients } \\
\hline
\end{tabular}

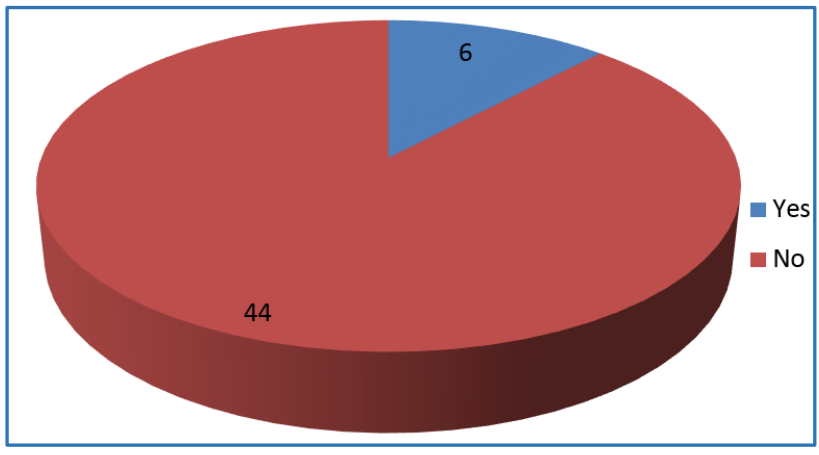

Graph 4. Distribution of Cases according to Psoriatic Arthritis

\begin{tabular}{|c|c|c|c|c|}
\hline \multirow{2}{*}{$\begin{array}{c}\text { Incidence } \\
\text { of DM }\end{array}$} & \multicolumn{2}{|c|}{ Cases } & \multicolumn{2}{c|}{ Controls } \\
\cline { 2 - 5 } & Frequency & Percent & Frequency & Percent \\
\hline Yes & 11 & 22 & 8 & 16 \\
\hline No & 39 & 78 & 42 & 84 \\
\hline Total & $\mathbf{5 0}$ & $\mathbf{1 0 0}$ & $\mathbf{5 0}$ & $\mathbf{1 0 0}$ \\
\hline \multicolumn{4}{|c|}{ Table 5. Prevalence of Diabetes } \\
Mellitus in Cases and Controls \\
\hline
\end{tabular}

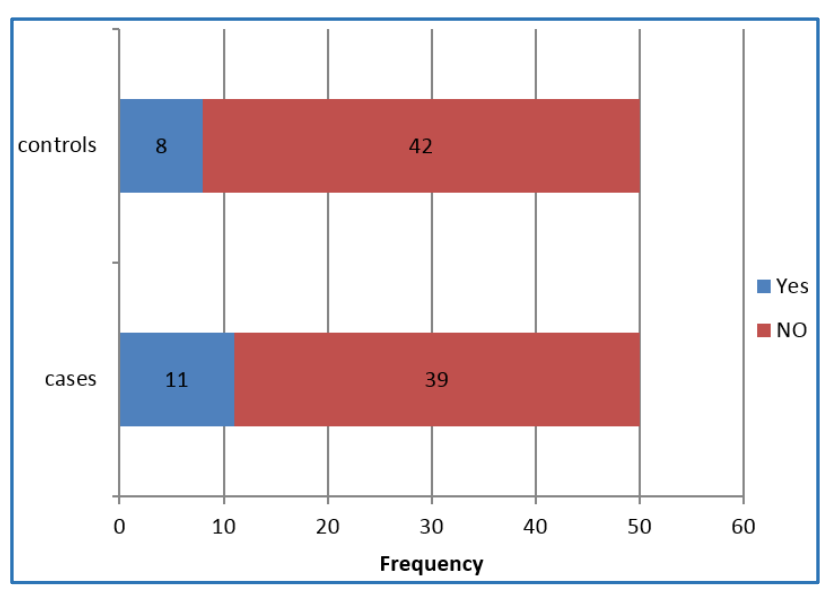

Graph 5. Prevalence of Diabetes Mellitus in Cases and Controls

\begin{tabular}{|c|c|c|c|c|}
\hline \multirow{2}{*}{ Incidence of HTN } & \multicolumn{2}{|c|}{ Cases } & \multicolumn{2}{c|}{ Control } \\
\cline { 2 - 5 } & No. & $\%$ & No. & $\%$ \\
\hline Yes & 08 & 16.0 & 04 & 8.0 \\
\hline No & 42 & 84.0 & 46 & 92.0 \\
\hline Total & $\mathbf{5 0}$ & $\mathbf{1 0 0 . 0}$ & $\mathbf{5 0}$ & $\mathbf{1 0 0 . 0}$ \\
\hline Table 6. Prevalence of HTN in Cases and Control \\
\hline
\end{tabular}

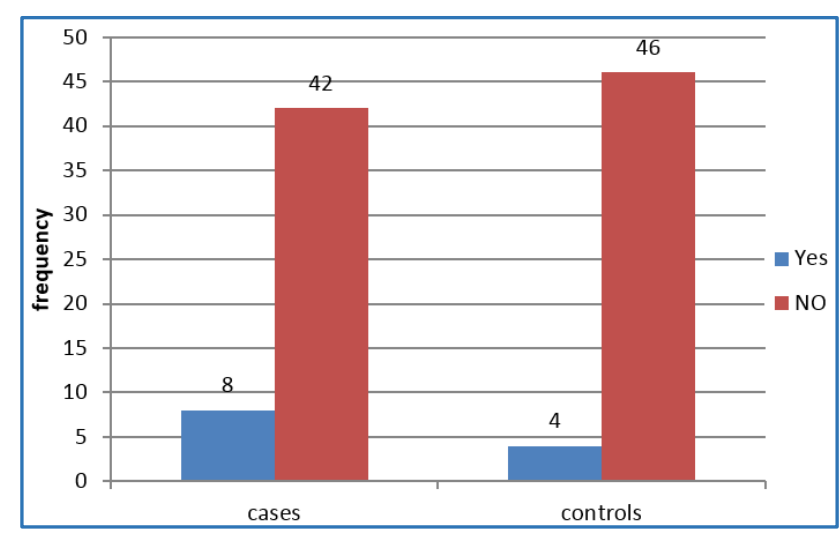

Graph 6. Prevalence of HTN in Cases and Control 


\begin{tabular}{|c|c|c|c|c|}
\hline Lipid Profile & Criteria & $\begin{array}{c}\text { Cases } \\
(n=50)\end{array}$ & $\begin{array}{l}\text { Control } \\
(n=50)\end{array}$ & $\begin{array}{c}\mathbf{p} \\
\text { Value }\end{array}$ \\
\hline \multirow{2}{*}{$\begin{array}{c}\text { Total } \\
\text { Cholesterol }\end{array}$} & $<250 \mathrm{mg} / \mathrm{dL}$ & $48(96 \%)$ & $49(98 \%)$ & \multirow{2}{*}{0.0001} \\
\hline & $>250 \mathrm{mg} / \mathrm{dL}$ & $02(4.0 \%)$ & $01(2.0 \%)$ & \\
\hline \multirow{2}{*}{$\begin{array}{c}\text { Serum } \\
\text { Triglycerides }\end{array}$} & $<170 \mathrm{mg} / \mathrm{dL}$ & $44(88 \%)$ & $45(90.0 \%)$ & \multirow{2}{*}{0.0001} \\
\hline & $>170 \mathrm{mg} / \mathrm{dL}$ & $06(12 \%)$ & $05(10.0 \%)$ & \\
\hline \multirow[b]{2}{*}{ HDL } & $<70$ & 48( & 49 & \multirow{2}{*}{0.0001} \\
\hline & $>70$ & 021 & & \\
\hline \multirow[b]{2}{*}{ VLDL } & $<34 \mathrm{mg} / \mathrm{dL}$ & $43(86 \%)$ & $45(90 \%)$ & \multirow{2}{*}{0.0001} \\
\hline & $>34 \mathrm{mg} / \mathrm{dL}$ & $07(14 \%)$ & & \\
\hline \multirow[b]{2}{*}{ LDL } & $<190 r$ & $47(94 \%)$ & 49 & \multirow{2}{*}{0.0001} \\
\hline & $>190 \mathrm{mg} / \mathrm{dL}$ & $03(6 \%)$ & & \\
\hline \multicolumn{5}{|c|}{ 7. Lipid Profile of Cases } \\
\hline
\end{tabular}

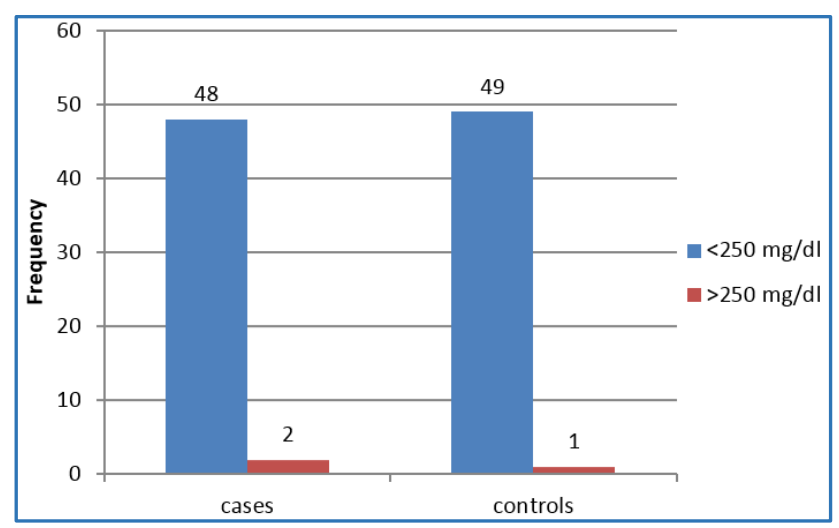

Graph 7. Distribution of Total Cholesterol Level in Cases and Controls

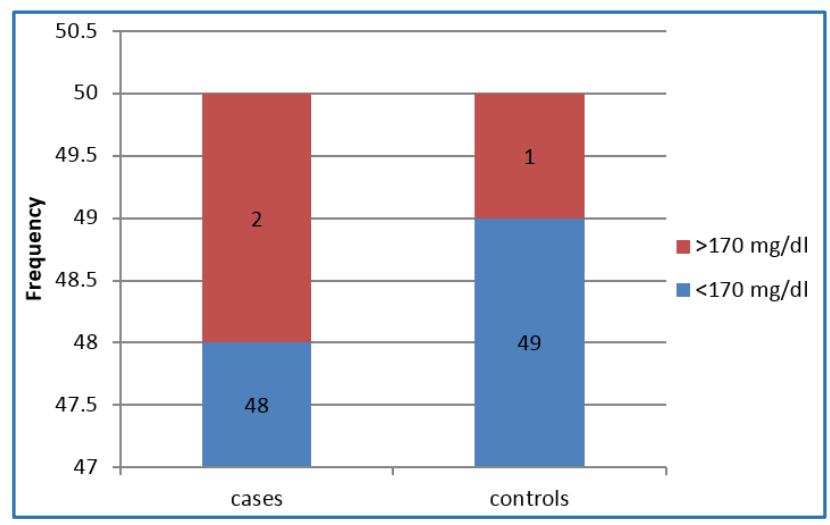

Graph 8. Distribution of Serum Triglyceride Level in Cases and Control

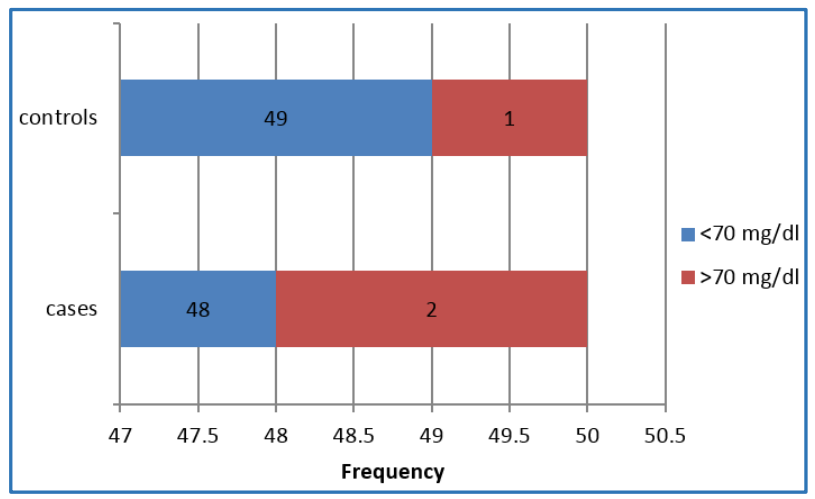

Graph 9. Distribution of HDL Level in Cases and Control

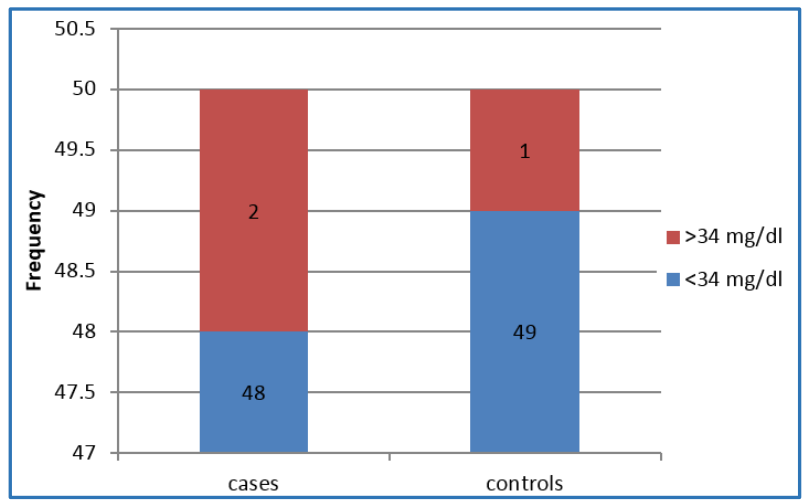

Graph 10. Distribution of VLDL Level in Cases and Control

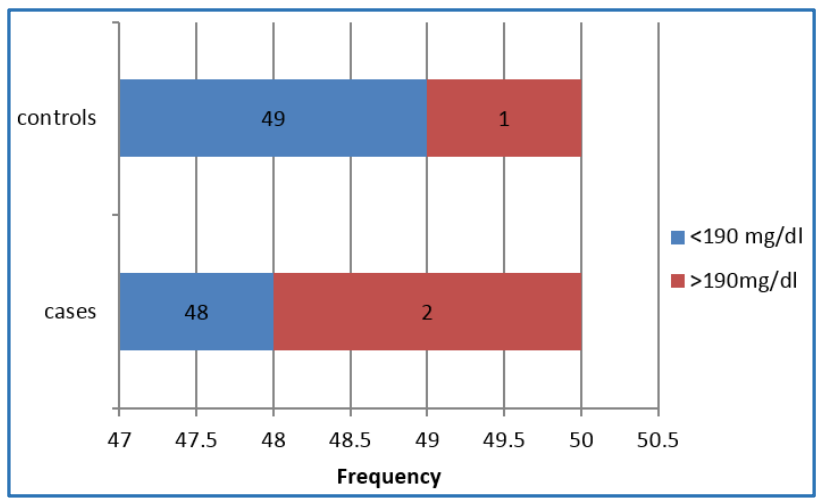

Graph 11. Distribution of LDL Level in Cases and Control

\begin{tabular}{|c|c|c|c|c|c|c|c|c|}
\hline & Group & $\mathbf{N}$ & Mean & Std. Deviation & $\mathbf{t}$ & df & $\mathbf{p}$ & Inference \\
\hline \multirow{2}{*}{ Age } & Cases & 50 & 37.26 & 14.09 & -1.023 & \multirow{2}{*}{98} & .309 & \multirow{2}{*}{ Not significant } \\
\hline & Controls & 50 & 40.20 & 14.64 & & & $(>0.05)$ & \\
\hline \multirow{2}{*}{$\mathrm{TC}$} & Cases & 50 & 198.46 & 26.61 & .137 & \multirow{2}{*}{98} & .891 & \multirow{2}{*}{ Not significant } \\
\hline & Controls & 50 & 197.74 & 26.02 & & & $(>0.05)$ & \\
\hline \multirow{2}{*}{$\mathrm{TG}$} & Cases & 50 & 148.16 & 63.19 & -1.682 & \multirow{2}{*}{98} & .096 & \multirow{2}{*}{ Not significant } \\
\hline & Controls & 50 & 163.46 & 11.96 & & & $(>0.05)$ & \\
\hline \multirow{2}{*}{ HDL } & Cases & 50 & 42.32 & 10.43 & 1.215 & \multirow{2}{*}{98} & .227 & \multirow{2}{*}{ Not significant } \\
\hline & Controls & 50 & 40.04 & 8.21 & & & $(>0.05)$ & \\
\hline \multirow{2}{*}{ VLDL } & Cases & 50 & 28.82 & 10.96 & .887 & \multirow{2}{*}{98} & .377 & \multirow{2}{*}{ Not significan } \\
\hline & Controls & 50 & 26.90 & 10.69 & & & $(>0.05)$ & \\
\hline \multirow{2}{*}{ LDL } & Cases & 50 & 153.10 & 20.34 & 2.193 & \multirow{2}{*}{98} & .031 & \multirow{2}{*}{ Significant } \\
\hline & Controls & 50 & 143.30 & 24.18 & & & $(<0.05)$ & \\
\hline \multirow{2}{*}{ TG/HDL } & Cases & 50 & 4.8580 & .99 & -.904 & \multirow{2}{*}{98} & .368 & \multirow{2}{*}{ Not significant } \\
\hline & Controls & 50 & 5.0224 & .83 & & & $(>0.05)$ & \\
\hline \multirow{2}{*}{ LDL/HDL } & Cases & 50 & 3.7864 & .97 & .600 & \multirow{2}{*}{98} & .550 & \multirow{2}{*}{ Not significant } \\
\hline & Controls & 50 & 3.6814 & .77 & & & $(>0.05)$ & \\
\hline
\end{tabular}




\section{DISCUSSION}

Psoriasis is a chronic and relapsing inflammatory skin disease. This study was undertaken to study one such debatable association. Lipid profile abnormality (fasting triglyceride $>150 \mathrm{mg} / \mathrm{dL}$ and HDL cholesterol $<40 \mathrm{mg} / \mathrm{dL}$ in men and $<50 \mathrm{mg} / \mathrm{dL}$ in female), increased fasting blood glucose levels ( $>110 \mathrm{mg} / \mathrm{dL}$ ), increased waist circumference (men $>40$ inches and female $>35$ inches) and increase in blood pressures ( $>130 / 85 \mathrm{mmHg}$ ), which collectively constitute the so called metabolic syndrome.

The chronic inflammation in psoriasis has an unfavourable effect on the cardiovascular risk profile. Multiple cardiovascular risk factors seem to be influenced; the blood pressure, oxidative stress, dyslipidaemia, endothelial cell dysfunction, homocysteine levels and blood platelet adhesion. 14,15

In our study 50 cases and 50 age, sex matched controls were recruited. Mean age of cases was 37.26 years, while mean age of the controls was 40.20 years. The samples were thus age matched ( $p$ 0.309). Maximum number of patients (26\%) of psoriasis belonged to age group of 31 - 40 years.

Out of 50 cases, 38 were males and 12 were females. Male: female ratio was 3.2: 1 . A high male preponderance seen in our study correlates with other published studies. Kaur et al ${ }^{16}$ found a sex ratio of 2.3: 1 , whereas Mehta et al a ratio of $4: 1$. Thus, the sex ratio in our study correlated with the above literature. The ratio in controls was 2:1.

In our study, PASI was used to grade the patients. As a definite literature regarding the classification of PASI into mild, moderate and severe is lacking, we classified the patients depending on the available studies. According to PASI, 2 patients $(4 \%)$ had mild psoriasis (PASI < 3), 30 patients $(60 \%)$ had psoriasis of moderate severity (PASI 3 $10)$, whereas 18 patients (36\%) had severe type (PASI > 10). Thus, 32 patients $(64 \%)$ had PASI score less than 10, which correlates with other studies. ${ }^{17,18}$

In our study, 6 patients had psoriatic arthropathy. Thus, the prevalence of psoriatic arthritis in our study period was found to be $12.0 \%$. In a study conducted on Indian patients by Prasad et al,19 prevalence of psoriatic arthritis in psoriasis patients was found to be $8.47 \%$. In another study conducted in India by Bedi et al,20 joint symptoms were present in $10 \%$ of psoriasis cases. Thus, the results of our study correlates with the findings of above study.

The prevalence of diabetes mellitus in cases of psoriasis was $22 \%$ as compared to $16 \%$ in controls. Thus, there was no significant increase in prevalence of diabetes in patients with psoriasis. The results were consistent with that of an Indian study by Alexander et al, which revealed a prevalence of diabetes in $13.1 \%$ of psoriasis patients. This is also in agreement with the study done by Sundharam, who showed a relationship between abnormal glucose tolerance and psoriasis. However, reports from Western literature contradict this finding. Neimann et al, Sommer et al, Shapiro et al and Cohen et al have all reported an increase in the prevalence of diabetes in patients with psoriasis.

However, no correlation of the prevalence of diabetes mellitus was found with the severity of disease ( $p$ value 0.4443 ) in our study.

The prevalence of hypertension in cases of psoriasis was $16 \%$ (8 patients) as compared to $8 \%$ (4 patients) controls. Thus, there was no significant increase in prevalence of hypertension in patients with psoriasis. However, no correlation of the prevalence of hypertension was found with the severity of disease ( $p$ value 0.218 ). The results were consistent with that of an Indian study by Alexander et al, which revealed a prevalence of hypertension in $8.1 \%$ of psoriasis patients. Cohen et al in their study reported that the prevalence of hypertension was significantly higher in psoriasis patients than controls (38.8\%, 29.1\% respectively). Similar results were noted by Sommer et al.

Serum lipid levels were analysed in cases and compared with controls. We did not find any difference in the total serum cholesterol composition in cases and controls. $96 \%$ of the cases of psoriasis had serum cholesterol values within the normal range as compared to $98 \%$ of controls. Thus, no significant difference in cholesterol values was seen in cases and controls ( $p$ value 0.001). The mean value of serum cholesterol in cases was $198.46 \mathrm{mg} / \mathrm{dL}$, which was comparable to the mean value in controls $197.74 \mathrm{mg} / \mathrm{dL}$ ( $\mathrm{p}$ value 0.309 ). Mallbris et al in a study on 200 psoriasis cases showed elevated total serum cholesterol, but the change was not significant. Rocha-Pereira reported increased cholesterol values in 38 psoriasis patients, whereas Piskin et al showed significantly raised levels in 100 patients.

The serum triglyceride composition varied in cases and controls. The mean value in cases was 148.16 , which was significantly lower than the mean value in controls which was 163.46 ( $p$ value: < 0.96). Serum triglycerides has been reported to be high in different studies. ${ }^{7}$ The mean values of HDL in cases and controls were 42.32 and 40.04 respectively, thereby showing no significant association ( $p$ value 0.227 ).

Piskin et al in their study also reported normal levels of HDL in psoriatic patients, while Rocha-Pereira reported decreased levels of HDL in psoriatic patients.

The mean values of VLDL in cases and controls were 28.82 and 26.90 respectively. No significant association was seen in VLDL values between cases and controls ( $p$ value 0.377). Other studies have reported an increase in the levels of VLDL in psoriatic cases.

Mean LDL values in cases was 153.10 , while mean value in controls was 143.30. The association was not found to be significant ( $p$ value 0.031 ). This result correlated with the study done by Uyanik on 72 psoriasis patients, wherein LDL levels in cases and controls were comparable. Rocha-Pereira also concluded the same finding from his study.

In our study was that there was no variation in the parameters of lipid profile according to the severity of psoriasis judged on the basis of PASI score. There was no association between derangements in lipid profile and the presence or absence of diabetes in these patients. Thus, diabetes could be ruled out as an underlying factor leading to derangement in lipid profile of psoriatic patients. There was no association between prevalence of hypertension and abnormalities in lipid profile. Thus, hypertension had no bearing on the lipid profile in these patients.

\section{CONCLUSION}

Males are more commonly affected with majority in the age group 31 - 40 years. DM, HTN may be chance association and may not be related to the severity of psoriasis. $4 \%(2$ patients) of the patients had mild disease, 60\% (30 patients) of the patients had moderate disease, while (18 patients) $36 \%$ of the patients had severe disease. Psoriatic arthritis was noted in $12 \%$ ( 6 patients) of the cases. 
Amongst the various lipid parameters slight elevation was found only in triglyceride values, while other parameters like HDL, VLDL, LDL and Total Cholesterol did not show any significant association. Further, there is no relationship between lipid parameters and severity of disease. In patients with psoriasis, derangements of lipids may be independent of DM and HTN.

This has important implications for treating dermatologist as it allows them to be more adventurous and aggressive in treating these patients, while simultaneously saving the cost of expensive unnecessary investigations that they may resort to rule out underlying metabolic syndrome. There may be additional metabolic and other risk factors involved for increased prevalence of metabolic syndrome in psoriasis patients.

\section{REFERENCES}

[1] Griffiths CEM, Camp RDR, Barker JNWN. Psoriasis. In: Burns T, Breathnach S, Cox N, et al. eds. Rook's textbook of dermatology. $7^{\text {th }}$ edn. Oxford: Blackwell Science 2005:1-35.

[2] Mallbris L, Larsson P, Bergquist S, et al. Psoriasis phenotype at disease onset: clinical characterization of 400 adult cases. J Invest Dermatol 2005;124(3):499504.

[3] Baker H. Psoriasis a review. Part 1. Dermatologica 1975;150(1):16-25.

[4] Linden KG, Weinstein GD. Psoriasis: current perspectives with an emphasis on treatment. Am J Med 1999;107(6):595-605.

[5] Raychaudhari SP, Rein G, Farber EM. Neuropathogenesis and neuropharmacology of psoriasis. Int J Dermatol 1995;34(10):685-93.

[6] Michael P, Schon W, Boehncke H. Psoriasis. New Eng J Med 2005;352(18):1899-912.

[7] Javidi Z, Meibodi NT, Nahidi Y. Serum lipid abnormalities and psoriasis. Indian J Dermatol 2007;52(2):89-92.

[8] Seishima M, Mori S, Noma A, et al. Serum lipid and apolipoprotein levels in patients with psoriasis. Br J Dermatol 1994;130(6):738-42.
[9] Seckin D, Tokgozoglu L, Akkaya S. Are lipoprotein profile and lipoprotein (a) levels altered in men with psoriasis? J Am Acad Dermatol 1994;31(3 Pt 1):445-9.

[10] Kural VB, Orem A, Cimsit G, et al. Evaluation of the atherogenic tendency of lipids and lipoprotein content and their relationships with oxidant-antioxidant system in patients with psoriasis. Clin Chim Acta 2003;328(1-2):71-82.

[11] Tekin NS, Tekin IO, Barut F, et al. Accumulation of oxidized low-density lipoprotein in psoriatic skin and changes of plasma lipid levels in psoriatic patients. Mediators Inflamm 2007;2007:78454.

[12] Cohen AD, Dreiher J, Shapiro Y, et al. Psoriasis and diabetes: a population-based cross-sectional study. J Eur Acad Dermatol Venereol 2008;22(5):585-9.

[13] Rosenberg P, Urwitz H, Johannesson A, et al. Psoriasis patients with diabetes type 2 are at high risk of developing liver fibrosis during methotrexate treatment. J Hepatol 2007;46(6):1111-8.

[14] Wakkee M, Thio HB, Prens EP, et al. Unfavorable cardiovascular risk profiles in untreated and treated psoriasis patients. Atherosclerosis 2007;190(1):1-9.

[15] Torkhovskaia TI, Fortinskaia ES, Ivanova LI, et al. Characteristics of lipid transposrt system in psoriasis. Vopr Med Khim 2002;48(3):297-303.

[16] Henseler T, Christopher E. Psoriasis of early and late onset: characterization of two types of psoriasis vulgaris. J Am Acad Dermatol 1985;13(3):450-6.

[17] Kremers HM, McEvoy MT, Dann FJ, et al. Heart disease in psoriasis. J Am Acad Dermatol 2007;57(2):347-54.

[18] Koba S, Hirano T, Sakaue T, et al. An increased number of very-low density lipoprotein particles is strongly associated with coronary heart disease in Japanese men, independently of intermediate-density lipoprotein or low-density lipoprotein. Coron Artery Dis 2002;13(5):255-62.

[19] Prasad PVS, Bikku B, Kaviarasan PK, et al. A clinical study of psoriatic arthropathy. Indian J Dermatol Venereol Leprol 2007;73(3):166-70.

[20] Bedi TR. Clinical profile of psoriasis in north India. Indian J Dermatol Venereol Leprol 1995;61(4):202-5. 